\title{
Fast-growing cervical mass: anaplastic thyroid carcinoma
}

\author{
Ana Coutinho Santos, ${ }^{1}$ Mariana Horta ${ }^{2}$
}

'Department of Radiology, Centro Hospitalar de Lisboa Ocidental, EPE, Lisbon, Portugal ${ }^{2}$ Department of Radiology, Instituto Português de Oncologia de Lisboa Francisco Gentil, EPE, Lisbon, Portugal

\section{Correspondence to} Dr Ana Coutinho Santos, a.icoutinho.santos@gmail.com

Accepted 26 January 2018

\section{DESCRIPTION}

An 81-year-old female patient noticed a left-side cervical lump with no associated symptoms 6 months before admission on our institute. Days before presenting to the Endocrinology Department, there was a sudden rapid growth of the neck mass, causing dysphagia for liquids and dysphonia, but no dyspnoea. The patient denied family history of thyroid pathology.

Clinical examination revealed a massive mass extending from the mandible angle to the supraclavicular region, occupying the anterior and both lateral cervical compartments, especially on the left side. The mass was fixed and of hard consistency, with associated bilateral cervical lymphadenopathies difficult to distinguish from the mass. Laboratory work-up identified hypokalaemia and hypernatraemia. The definite diagnosis of anaplastic thyroid carcinoma (ATC) was obtained by fine needle aspiration cytology.

Contrast-enhanced CT (figure 1) was performed for tumour staging and showed a heterogeneous and infiltrative mass, with origin on the left lobe of the thyroid gland, measuring approximately $12 \times 8 \times 14 \mathrm{~cm}$ (great diameters in transversal, anteroposterior and craniocaudal axis, respectively). The tumour incarcerated the left common carotid artery, which was permeable, and caused thrombosis of the ipsilateral internal jugular vein. The air column was deviated to the right, with a minimal diameter of $6 \mathrm{~mm}$ at the supraglottic level. The lesion extended to the skin on the left side and to the prevertebral space. The bone integrity was maintained. There were also multiple lymphadenopathies on level II bilaterally, and the remaining lymph node cervical levels were occupied by the tumour. There were no lung metastases.

The patient was admitted to supportive medical care, namely nutritional and hydration, and palliative radiotherapy. There was rapid disease progression, as the mass continued to enlarge in spite of radiotherapy, causing cervical pain, complete dysphagia, and progressive dyspnoea and stridor. Unfortunately, the patient died 1 week after admission.

ATC is a rare malignancy, accounting for $1 \%-2 \%$ of all thyroid cancers, and one of the most aggressive tumours, with a median survival of 3-5 months following diagnosis. ${ }^{12}$ Nearly $50 \%$ of patients have metastatic disease at initial diagnosis. ${ }^{3}$ This tumour
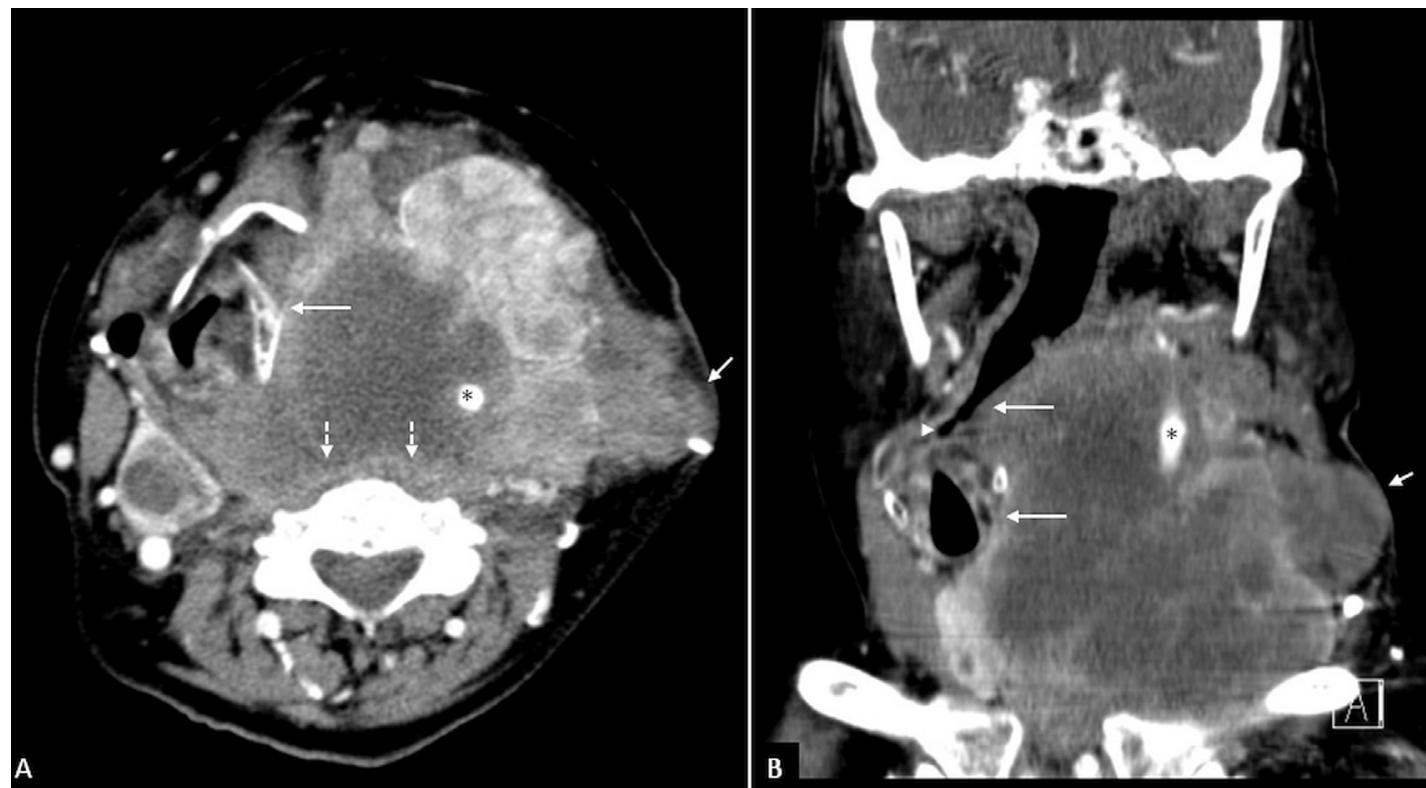

Figure 1 Cervical contrast-enhanced CT on axial (A) and coronal (B) planes depicting a massive, expansive and infiltrative lesion originating from the left lobe of the thyroid gland and occupying the anterior and lateral compartments of the neck, especially on the left side. The mass is heterogeneous, predominantly hypodense, suggesting extensive necrotic component due to the aggressive behaviour. The lesion incarcerates the left common carotid artery $\left({ }^{*}\right)$, which is still patent, and invades and causes thrombosis of the ipsilateral internal jugular vein. There is extension to the skin on the left side (short arrow), involvement of the prevertebral space (dashed arrows on A), and deviation of the larynx and air column to the right (long arrows) causing marked reduction of its lumen (arrowhead on B). 
often originates in a pre-existing differentiated thyroid cancer but can also occur de novo. ${ }^{2}$ Anaplastic transformation must be suspected if patients present with a rapidly enlarging, firm, palpable neck mass, as well as hoarseness, neck pain, dysphagia and/or dyspnoea, which should prompt a rapid assessment and biopsy of the lesion. ${ }^{23}$

Clinical management of ATC is multidisciplinary and requires referral to a centre with experience. ${ }^{2}$ Conventional therapies, including surgery, radiotherapy and systemic chemotherapy, have limited efficacy. ${ }^{3}$ Molecular targeted therapies such as receptor tyrosine kinase inhibitors are promising treatment modalities. ${ }^{13}$ Between 20\% and 50\% of ATCs harbour activating B-Raf kinase (BRAF) V600 mutation, and the combination of dabrafenib/ trametinib showed incredible efficacy in patients with locally advanced or metastatic BRAF V600E-mutated ATC. Hence, BRAF mutation should be obtained on all patients with ATC at diagnosis. ${ }^{1}$ Lenvatinib, a multikinase inhibitor, showed moderate efficacy in patients with ATC with a manageable safety profile. ${ }^{3}$

Contributors ACS was responsible for the study concept and design, revision of the literature, and drafting of the manuscript. MH contributed to study supervision and critical revision of the manuscript. Both authors were responsible for acquisition, analysis and interpretation of the data.

Competing interests None declared.

Patient consent Obtained.

\section{Learning points}

- Anaplastic thyroid carcinoma is a rare and aggressive form of thyroid cancer that represents diagnostic and therapeutic challenges. It often originates in a pre-existing thyroid cancer lesion but can occur de novo.

- Most patients present with a rapidly enlarging, firm, palpable neck mass, dysphagia and dyspnoea.

- Imaging is essential to tumour staging and to define the plan of treatment, which must be implemented rapidly due to the poor prognosis.

Provenance and peer review Not commissioned; externally peer reviewed. (c) BMJ Publishing Group Ltd (unless otherwise stated in the text of the article) 2018. All rights reserved. No commercial use is permitted unless otherwise expressly granted.

\section{REFERENCES}

1 Subbiah V, Kreitman RJ, Wainberg ZA, et al. Dabrafenib and trametinib treatment in patients with locally advanced or metastatic BRAF V600-mutant anaplastic thyroid cancer. J Clin Oncol 2018;36:7-13.

2 Cabanillas ME, McFadden DG, Durante C. Thyroid cancer. Lancet 2016;388:2783-95.

3 Tahara M, Kiyota N, Yamazaki T, et al. Lenvatinib for anaplastic thyroid cancer. Front Oncol 2017:7:1-7.

Copyright 2018 BMJ Publishing Group. All rights reserved. For permission to reuse any of this content visit

http://group.bmj.com/group/rights-licensing/permissions.

BMJ Case Report Fellows may re-use this article for personal use and teaching without any further permission.

Become a Fellow of BMJ Case Reports today and you can:

- Submit as many cases as you like

- Enjoy fast sympathetic peer review and rapid publication of accepted articles

- Access all the published articles

Re-use any of the published material for personal use and teaching without further permission

For information on Institutional Fellowships contact consortiasales@bmjgroup.com

Visit casereports.bmj.com for more articles like this and to become a Fellow 